\title{
Semblanza intelectual y moral de Ricardo Rojas
}

\begin{abstract}
Conocí a Ricardo Rojas allá entre 1904 y 1905 en las tertulias de "La Brasileña", café situado en la calle Maipú a la altura de Cangallo, donde solian reunirse de noche unos cuantos periodistas y escritores, los ya veteranos Roberto Payró y Joaquín de Vedia, alguna vez Florencio Sánchez, lanzado a la popularidad en 1903 por M’bijo el dotor, y más asiduos, Emilio Becher, Atilio Chiáppori, Alberto Gerchunoff, Emilio Ortiz Grognet y Alfredo Bianchi, que fue quien me arrimó a la mesa acostumbrada. Casi todos ellos procedían de la revista Ideas, fundada por Manuel Gálvez y Ricardo Olivera, éste muy pronto desgarrado de la militancia literaria para seguir otros caminos por donde alcanzaría altos cargos en la diplomacia. Ideas había agrupado de 1902 a 1904 a los talentos más vivaces de la joven generación que empezó a abrirse paso en el periodismo y las letras a comienzos del siglo, de la cual eran entonces las mayores esperanzas Ricardo Rojas y Emilio Becher. Precisamente Rojas ilustró muchos años después la tertulia de Ideás con recuerdos y nombres en la hermosa semblanza espiritual que trazó de Becher, el finísimo ensayista y crítico malogrado por el alcohol, el escepticismo y la abulia. Lo hizo cuando prologó el manojo de páginas que reunió su devoción al querido y admirado compañero y publicó el Instituto de Literatura Argentina de la Facultad de Filosofía y Letras por él dirigido. ${ }^{1}$
\end{abstract}

Gallardo mozo de rostro trigueño, melena bravía, firme bigote sobre labios carnosos, y oscuros ojos pensativos, siempre trajeado de negro, de negra corbata voladora y chambergo altivo, tal como lo teconozco en el

1 Emilio Becher, Diálogo de las sombras y otras páginas (Buenos Aires, Facultad de Filosofía y Letras, Instituto de Literatura Argentina, 1938). 
retrato que entonces trazó de él Fermín Arango, ya era el autor de $L a$ vidtoria del hombre. Entre Las montañas del oro, de 1897, y Los crepuisculos del jardín, de r905, el primero y el segundo libro de Lugones, si exceptuamos Castalia bárbara del boliviano Ricardo Jaimes Freyre, la lírica argentina que aprendía nuevas formas expresivas y métricas en los parnasianos y simbolistas franceses o en D'Annunzio, no había producido otro libro de mayor significación. En verdad, La victorict del hombre, ambicioso poema cíclico, era de acentuada inspiración huguesca, solemne y elocuente como una sucesión de oraciones tribunicias, pródigas en interrogaciones, apóstrofes y epifonemas. Al magnífico abuelo de La leyenda de los siglos habían de nacerle arrogantes nietecitos en la América Hispana, así como había dado hijos de la robusta talla de Andrade. ¿Y qué sino un cachorro de Hugo era el Lugones tonante de La voz contra la roca, y el anterior del olvidado poema La gesta magna? Hugo le prestaría a Rojas, para el epígrafe de su libro, concebido al salir de la adolescencia, dos versos de La leyenda de los siglos, y sería el primero de los cuatro "espíritus en marcha" cantados en el poema: los otros tres, Zola, por supuesto el utopista de los Evangelios, Castelar -adviértase-y Sarmiento. Conforme a las alegorías de filiación huguesca todavía vigentes, cantaba el joven poeta en versos sonoramente forjados, a través de imágenes tomadas de la historia y la naturaleza, los pasos del hombre con sus dolores y esperanzas hacia la conquista de un nuevo ideal. Tal como más tarde construiría sobre mitos poéticos una filosofía de la evolución del espíritu americano, la tendencia a pensar por confesados mitos filosóficos ya se hacía presente en sus primeros versos. Pero si el acento oratorio y profético fue el dominante en sus poesias, afirmaríamos una falsedad si lo dijéramos el único. Pocos años después el autor de El socio lírico, prólogo de Los lises del blasón, diría de su musa que era confusa y varia como la vida, $y$, en efecto, en aquel libro supo pasar con pie ágil de lo elegíaco a lo satírico, de lo grave a lo risueño, lo último tal como ló hizo en los versos tiernos y brincantes del "scherzo" en la Sonata del tiempo pasado:

Campana aldeana, címbalo de abril, lengua dulce y vana de la azul mañana, canta mi lejana leyenda infantil, cántala, campana, címbalo de abril. 
Retrocedo a los años en que nos hicimos amigos. Êl ya había truncado entonces los estudios de abogacía a poco de iniciados. La pluma y la cátedra serían su solo sustento. En la cátedra secundaria había sido nombrado en r904. Refiriéndose a su vocación por la enseñanza, pudo decir treinta años después: "hice voto de soledad al abrazar esta otra profesión, sin apartarme de mi vocación literaria". Periodista de clara inteligencia y estilo recio, pronto haría prestigioso en las columnas de La Nación el seudónimo de "Wilson", así como hizo Becher contemporáneamente en las mismas columnas, de codiciada lectura los artículos de "Stylo". No lo tuvimos los fundadores de Nosotros entre los colaboradores de los primeros números, publicados en 1907, como lo fueron sus amigos Becher, Chiáppori, Gerchunoff y Ortiz Grognet. Pero desde la iniciación contamos con su consejo y su apoyo. Publicamos su primera colaboración en junio de 1908. Nos llegaba de Pompeya. Era un extenso artículo titulado La boja de parra, defensa alarmada y acongojada del desnudo en el arte, cuando la pudibundez aldeana, inspirada y estimulada por el clero, amenazó de muerte los mármoles y alegorías estimados licenciosos con que la Municipalidad había decorado algunos paseos de Buenos Aires. Por esos mismos días la estulta censura social obligaba a la empresa de la Ópera a desistir de poner en escena Salomé de Strauss, y pocos años antes se le había prohibido a Eleonora Duse representar La abadesa de Jouarre. A fines de 1907 habíamos despedido a Rojas con un banquete. Se iba a Europa, donde, en Francia, en España, en Italia y en Inglaterra fue cordialmente acogido en los círculos intelectuales y publicó en París, El praís de la selva y Cosmópolis, con el acreditado sello de Garnier, y en Valencia El alma española, en las difundidas ediciones valencianas de Sempere. Las correspondencias a La Nación afirmaron su prestigio. Una gran fiesta fue el banquete con que se le recibió al regreso. La of reció su entrañable amigo Atilio Chiáppori y también hablaron Martiniano Leguizamón y Alfredo Palacios. Lagrimeó un bello soneto Charles de Soussens. En su discurso adelantó Rojas la política anticosmopolita y nacionalista que inspiraría su obra entera. Había llevado a Europa una misión oficial: informar sobre la enseñanza de la historia en las escuelas del Viejo Mundo. La cumplió escribiendo el voluminoso libro titulado La restauración nacionalista, publicado en I 909 , en el cual expuso en forma orgánica y con frecuente acento polémico sus reflexiones sobre la necesidad de robustecer el espíritu nacional por medio de la escuela y combatir el descastamiento del país, originado en la avasalladora inmigración extranjera. A sus diferentes tesis opuse entonces con brío no menos polémico 
y con algún juvenil atrevimiento (Rojas me llevaba cinco años) convicciones distintas sobre el futuro de la Argentina por obra de los extranjeros incorporados a la vida del país, asimilados por la acogedora tierra. ${ }^{2}$ Fuimos colegas cordiales y continuamos siendo amigos en el Colegio Nacional Manuel Belgrano, en cuyas aulas enseñamos largos años; pero siempre tuve la impresión de que entre el apologista de la indianidad, de antigua estirpe hispanoamericana, y el argentino de la primera generación, de procedencia "gringa", existía una desinteligencia espiritual de fondo. Esta desinteligencia temperamental quizá la ahondé yo, sin que se quebrara nuestra amistosa relación, cuando hice razonados reparos a su libro $L a$ argentinidad.3 Digno heredero de su estirpe y de su tierra santiagueña, pisada antes de la conquista por la civilización incaica, Rojas, animado por una especie de fatalismo racial y telúrico, veía la historia de su patria desarrollarse teleológicamente hacia fines como señalados providencialmente por el dedo de Dios. La Idea hegeliana, en este caso "la argentinidad, la conciencia y la idea de un pueblo nuevo", se realizaba en nuestra historia, era su Deus ex-machina. De tal idea él era el profeta, el augur, el vate. Todas las cosas parecían hacerle signos misteriosos. Alguna vez habló de su "propensión druídica", de la "emoción atávica y sacerdotal" que le humedecía los ojos de lágrimas; se preguntó si el derfumbamiento de la Piedra movediza ("la piedra sagrada") no sería "una venganza de nuestros dioses o el anuncio de un gran castigo para su pueblo", así como veía en aquella piedra "uno de los mayores signos de elección, entre tantos que la Providencia ha dispensado al territorio de nuestra patria" - decía.4

Quizá por estas y parecidas razones no siempre contó con la adhesión sin ambages de los escritores de promociones posteriores, aun respetándosele por su talento y la dignidad de su vida, por provenir los más de aquéllos de sangres diferentes, inaptas para admitir la transfusión de sentimientos e ideales que, siendo justificadamente válidos en la llamada Indoamérica del Pacífico y el altiplano, no lo son en la pampa poblada y transformada por la inmigración europea con predominación latina.

Parece obvio notar que el argentinismo de Rojas y la filosofía de la nacionalidad que sobre ese sentimiento él levantó en varios de sus libros

2 Roberto F. Giusti, "La restauración nacionalista por Ricardo Rojas", Nosotros, t. V, No 26, febreto 1910, pp. 139-156.

Roberto F. Giusti, La argentinidad, Nosotros, t. XXV, $\mathrm{N}^{9} 94$, febrero 1917, pp. 254-264 (reproducido en Crítica y Polémica, Buenos Aires, 1917).

4 "La piedra muerta", artículo publicado en La Nación de Buenos Aires el $1^{\circ}$ de marzo de 1912. 
desde $E l$ país de la selva, concebido antes de los veinte años, si bien acabado y publicado en 1907 , no tienen afinidad alguna con el nacionalismo cerril, agresivamente xenófobo hasta llegar a la persecución racial y al crimen públicamente aconsejado y en ocasiones cumplido. Aquél entroncó en nobles mitos poéticos, en la historia, las leyendas y el arte de América, en la conjunción, soñada en un plano superior, de la cultura occidental y la indígena americana y tuvo diversa expresión en la lírica y el ensayo del utopista de Eurindia, en sus estudios críticos e históricos, biografías, meditaciones estéticas y teatro; el otro, que empezó por la asimilación de las doctrinas de la Action Française, fue penetrado a poco andar por la ideología fascista y sus métodos violentos, hasta despeñarse, en algunos de sus secuaces, en la delincuencia hitlerista. Nuestro poeta ambicionó desempeñar el papel de guía y maestro de su pueblo y lo hizo por diferentes caminos, todos ellos limpios. El año I9I9, a poco de concluida la primera guerra mundial, leyó en el teatro Odeón un manifiesto a la juventud con la esperanza de reclutarla para el cumplimiento de altas tareas cívicas y morales. No tuvo éxito en aquella empresa de noble proselitismo propugnada en una extensa "Profesión de fe de la nueva generación", a la cual invitaba a formar una Alianza de espíritu democrático y liberal, más allá y por encima del ideario de los viejos partidos que habían gobernado la República hasta entonces. Más adelante se sintió atraído por el mesianismo de Hipólito Irigoyen. El proceso de su conversión al radicalismo paréceme recordar que se produjo en el tiempo en que se vio surgir avasalladora en 1927 la candidatura del anciano y enigmático caudillo a un segundo período presidencial. Rojas, que lo había combatido en la discutida primera presidencia, oponiéndose a su política neutralista durante la guerra mundial, y que había predicado en aplaudidas arengas el alineamiento junto a Francia e Inglaterra contra Alemania, se convirtió a la política nacional de Irigoyen, contagiado por el fervor de las masas que en las elecciones del primero de abril de 1928 habrían de llevarlo por segunda vez a la Casa Rosada. Debió de ser a fines de 1927 cuando en una de nuestras matinales pláticas él me disparó a boca de jarro una pregunta que en el momento me sorprendió en sus labios: "QQué piensa Ud. de este fervor popular por Irigoyen?" Procuré darle mis explicaciones políticas y de psicología social. "No, me dijo él, sentencioso, no es eso: el fenómeno es puramente religioso". Comprendí enseguida, conociendo su idiosincrasia espiritual, que el misticismo de las masas habia hecho presa también en él. Y asi fue. La afiliación se produjo en I930, después del movimiento cívico militar del 6 de septiembre que derribó al anciano 
presidente. Desde entonces se entregó con pasión al credo que habíd abrazado, al cual procuraría dar más alto sentido en su libro $E l$ radicalismo de mañana, y por él sufrió sinsabores y persecuciones, incluso el confinamiento en la inhóspita Ushuaia. Ante la reacción oligárquico-militar que sobrevino después del 6 de septiembre bajo el gobierno "de facto" del General Uriburu, supongo que en su fuero íntimo Rojas hizo una tabla comparativa de las culpas de unos y de otros, poniendo de un lado los errores cometidos por el caduco y ya maniático presidente y por su mayoría parlamentaria obsecuente y arbitraria, sorda a todas las admoniciones de la prensa y la oposición, del otro, la desviación de un movimiento - explicable en su origen, aunque peligrosísimo para el porvenir de las instituciones civiles-, hacia un régimen impregnado de la ideología totalitaria fascista, tendiente a implantarla en la Argentina, echó sumas y eligió. Desde la mocedad había hecho voto de estudio y alejamiento de la política... "Creía, escribió en el prólogo de su libro sobre Cervantes, fechado en Ushuaia en I934, que la Argentina hallábase encaminada, dentro de su Constitución, a la realización paulatina y pacífica de las esperanzas que le dieron origen como República independiente. Constituido el Estado, creí que a nuestra patria le restaba formar un pueblo, y ésta era una empresa de educación. Sin embargo, últimamente, vi quebrarse nuestras instituciones, y consideré deber ineludible sactificar mi paz intelectual para defender la ciudadanía".

Lo cierto es que el demócrata que siempre alentó en él, creyente sin vacilación en la eficacia civilizadora de la tradición política de mayo, jamás fue contaminado por las doctrinas exóticas abrazadas por los pretensos nacionalistas criollos, como le ocurrió al ex anarco-socialista Leopoldo Lugones, pasado en r923 al "culto de la espada" y a la reverencia de los gobiernos fuertes.

Así como fue firme la conducta de Rojas, irreductible opositor al gobierno "de facto" y al del general Justo que le sucedió, no transigió con el del demagogo pronto convertido por ineluctable ley psicológica e histórica en dictador y en el andar de los días degenerado en tirano voraz y megalómano. ¿Quién más representativo que Rojas para ser proclamado candidato a senador por la Capital por la Unión Democrática que en 1946 creyó, acompañada por la ilusión de algunos millones de argentinos, oponerse a la ascensión a la presidencia del vociferador descamisado? Ya había dejado Rojas entonces sus cátedras y trabajaba en ilustrar la vida titánica de Sarmiento como antes lo había hecho con la ejemplar de San Martín. Cuando todavía estaba en ellas no faltó quien sugiriera bajo la 
presidencia del general Justo, al ser confinado el ya ilustre maestro, de enero a mayo de 1934 en la Tierra del Fuego, después de la abortada intentona subversiva de la Unión Cívica Radical, con la cual coincidió un discurso suyo pronunciado en el Congreso del Partido celebrado en Santa $\mathrm{Fe}$, que se lo destituyera de las cátedras. Tuve la suerte de poder aconsejar con la poca autoridad política de que yo gozaba en esos días, que no se cometiera tal desatino. Los altos funcionarios del Ministerio de Instrucción Pública supieron detenerse ante la figura eminente del profesor y el escritor que tantos servicios había prestado a la cultura nacional.

En el confinamiento de Ushuaia se dio nobles temas de distracción. Allí dio forma definitiva a su notable libro sobre Cervantes, valiéndose de los borradores acumulados en la cátedra y elaborados durante unos cuatro lustros. Allí escribió su libro sobre la Tierra del Fuego, publicado más tarde en los suplementos dominicales de La Nación desde agosto de r94I hasta enero de 1942 con el título de Archipiélago. Conviene notar que cuando el mismo 1942 lo editó en libro, omitió dignamente en esa obra dictada por el patriotismo, el menor desahogo personal.

Lo vi volver con resignada modestia a sus cátedras acabado el confinamiento en el sur. Y vi más, y no sin indignación: que, no ya por el deseo de molestarlo, pues no creo que hubiera tal intención, sino por un miope espíritu burocrático, se empleara a Ricardo Rojas a la par del último aprendiz de profesor frescamente nombrado, en la corrección de las pruebas escritas de ingreso a la enseñanza secundaria. En mi opinión estas no son expresiones ejemplares de igualitarismo democrático sino torpes nivelaciones desconocedoras de los valores intelectuales y morales, incongruencias de la carrera del profesorado en la Argentina, las cuales hacen posible que un escritor insigne, un ex-Rector de la Universidad de Buenos Aires, aun deba ganarse la vida, robándole horas preciosas a sus trabajos literarios, en la corrección de las haches sobrantes en los palotes de los niños. Un almirante encargado de mandar ciertas horas del día un remolcador no ofrece imagen más incongruente. Lo vi cumplir la muy humilde y enojosa tarea sonrientemente resignado.

A la cátedra universitaria había llegado antes de los 30 años. Primeramente enseñó en la Facultad de Humanidades de La Plata, llevado por otro grande argentino, Joaquín González. Allí organizó con sus alumnos en I9ro una recordable bibliografía de Sarmiento y llevó a cabo en I9I6 una edición de las Poesias de Cervantes, en cuyo prólogo revisaba los juicios tradiçionales sobre el autor del Quijote en cuanto poeta lírico. 
Más tarde, desde I9I9, dictaría como titular la cátedra de Literatura Castellana en la Facultad de Filosofía y Letras de Buenos Aires, donde dio ante auditorios numerosos, cursos intensivos sobre el mismo Cervantes, el Cantar de mio Cid, la lírica, los orígenes del teatro, la técnica de la prosa, el Siglo de Oro, los autos sacramentales, Lope y otros temas de parecido ahondamiento en las letras españolas. Pero con anterioridad había sido memorable el día en que inauguró en la misma Facultad la cátedra de Literatura Argentina, la primera que hubo en el país. La hizo crear para él Rafael Obligado, entonces vicedecano de la Facultad. Ambos, el poeta ilustre del Santos Vega y el de La victoria del bombre, leyeron el 7 de junio de I9r3 conceptuosos discursos inaugurales, que publicó la revista Nosotros. En el suyo Rojas trazó los lineamientos de una investigación que daría origen a su obra mayor, La literatura argentina, título de la primera edición de su Historia. Avisó entonces que la fundación de la cátedra señalaba un nuevo rumbo en nuestra historia universitaria. Dijo: "El maestro que la inaugura esta tarde, deberá no solamente dictar sus lecciones, sino crear esa nueva asignatura sin bibliografía. Maestro y alumnos deberemos entrar en este nuevo campo de los estudios argentinos, disipando muchas leyendas, rectificando numerosos errores, desvaneciendo tradicionales prevenciones y descubriendo acaso valiosas noticias en olvidados archivos, como los que dejaron Segurola, Olaguer Feliú, Mitre, Lamas, Trelles, Bustamante o Juan María Gutiérrez". No se le ocultaban empero las dificultades, a las que oponía, no la presunción de su ciencia, sino la vocación patriótica y la experiencia literaria.

En páginas todavía inéditas de próxima publicación, yo he juzgado con rectitud, que no ha eludido los debidos reparos, la vasta obra que surgió de esa cátedra. No cabe tal juicio crítico en la semblanza que estoy trazando del colega y el amigo, siguiendo con libertad discontinuamente sus pasos. Pero debo oponerme a las opiniones ligeras que condenan frívolamente un esfuerzo excepcional por el mérito y los resultados en un ambiente literario nada propenso a la persistente labor diurna y nocturna. Aquí podría repetirse lo que escribió Fray Luis de León de cualquier posible censor de sus traducciones: "haga prueba de sí, y entonces podrá ser que estime mi trabajo más".

Lo cierto es que entre los críticos argentinos, Rojas ha sido el único que en la cátedra y en el libro dio unidad en un sistema orgánico, que superó el manual escolar y el libro de divulgación, a los juicios particulares sobre las obras y autores que llenan casi dos centurias de actividad literaria. Juicios los suyos, si no todos de igual valor, escritos con ecléc- 
tica comprensión de las más diferentes manifestaciones literarias, tal cual prometían la cultura y el gusto del crítico, formado en la confluencia de $\tan$ diversas corrientes artísticas o ideológicas como fue en la Argentina la iniciación del siglo presente. Su Historia no es propiamente una atrevida revisión de valores literarios, por más que no falte en los juicios franqueza, si atenuada por un legítimo sentido de la relatividad y por la simpatía nacionalista, no menos estimable en cuanto reduce a sus justas proporciones a más de un escritor excesivamente agrandado por el fetichismo patriótico. Pero es el basamento de la columnata. Con posterioridad se iría viendo cuáles eran las columnas sólidas del edificio. Pueden ser desechados, como tejidos con la materia de que están hechos los sueños, los mitos entre los cuales él se movía con paso lento y ademanes litúrgicos a semejanza de un hierofante en el tempo, por ser de discutible valor científico; con todo, seguirá siendo válido y útil el cuadro donde el historiador compuso y correlacionó las manifestaciones culturales y literarias argentinas y los factores ponderables que las han determinado. Los mismos que no se han reconciliado todavía con esta obra ingente, acuden a ella a escondidas y seguirán consultándola por largos años. Ya lo previó el autor cuando dio a luz en 1917 el primer tomo, relativo a los gauchescos. Advirtió: "Dentro de varios años habrán pasado a categoría de lugares comunes algunas noticias que aquí divulgo con las ideas del sistema estético que las ensambla y las explica. Muchos habrán ahijado noticias e ideas en que acierte; y no me querellaré de su actitud si no murmuran de algún pequeño ertor no corregido, fingiendo desdeñar el libro de que se sirvieron".

Una alusión desdeñosa y butlona de Groussac vale como sentencia inapelable para muchos, como si pudiera haberlas en materia literaria. La consabida condenación del floripondio sigue repitiéndose papagayescamente y sin examen, aun cuando puede desafiarse a muchos repetidores a que digan qué entendía por el tal floripondio Groussac.

Recordemos ante todo que aquella flor grande que solían figurar en los tejidos nuestras abuelas, de cuyo asiduo cultivo acusó Groussac malévolamente a Rojas, no fue referida propiamente a la Historia de la litevatura argentina; sólo apareció en el "post-scriptum" que cerró la reedición de los famosos artículos polémicos sobre los Escritos de Mariano Moreno, cuando los reprodujo el año 1924 en el volumen titulado Crítica literaria.

Reaccionó Groussac en tal "post-scriptum" con su acostumbrada acritud contra la que calificó una "impettinencia" de Rojas, que por tal tuvo la alusión indudablemente irónica al tropezón que años antes había dado 
el ilustre bibliotecario al conjeturar como autor del falso Quijote al valenciano José Martí, tropezón nunca consentido hasta el día de su muerte, a pesar de la prueba, en apariencia inequívoca, de Menéndez y Pelayo. La imagen del floripondio fue, pues, en ese pasaje, un recurso polémico de dudosa ley: una agudeza respondiendo a otra agudeza. Por lo que concierne a la Historia de la literatura argentina recordaré que pretendió ajusticiarla el crítico anciano y ya ciego, al final del malhumorado prefacio de aquel mismo libro, sin nombrarla, "después, dijo, he oído con resignación, dos o tres fragmentos de prosa gerundiana de cierto mamotreto públicamente aplaudido por los que apenas lo han abierto", por donde se consideraba autorizado para no seguir adelante, "ateniéndome por ahora, agregaba, a los sumarios e índices de aquella copiosa historia de lo que, orgánicamente, nunca existió". El juicio acerca del contenido era notoriamente injusto y además se fundaba en una inexactitud, pues no es cierto que "la primera y más indigesta parte de la mole", según la apreciación despectiva de Groussac, ocupara tres tomos de los cuatro de la primera edición, como él afirmó, estimándolos sin duda solamente por el tacto. Estos tres tomos, particularmente el segundo y el tercero, contienen algo más que balbuceos de indígenas o mestizos, remedos deformes de crónicas o poemas peninsulares y nociones bobas de etnografía y folklore", pues comprenden también "aquellas tentativas de emancipación espiritual que germinaría más tarde, a la par de la política, y al calor e influjo de esta misma", como el crítico, con forzada indulgencia y contradiciéndose con aquello de que nunca existió orgánicamente una literatura argentina, reconocía haber sucedido en nuestra historia literaria.

Para alcanzar la condensación de una literatura en pocos centenares de páginas hay que acometer la labor previa de acumulación y clasificación de los materiales, que es lo que hizo el profesor e historiador argentino, proyectando su mirada más allá de la crítica propiamente literaria, hasta abarcar la historia entera de la literatura entendida en sentido genérico y lato. El primero en saber qué tenía entre manos era él. Suyas son estas palabras: "Nuestra literatura colonial [...] no es sino documentación bibliográfica y hay que llegar a Juan Cruz Varela, un poeta de la Revolución, para tocar los aledaños del arte".

Pensemos ahora unos minutos sobre el floripondio y la no menos traída y llevada prosa gerundiana. En cuanto a estilos caben muchos, sin pelearse, en la hospitalaria república de las letras, sea democrática o aristocrática. Caben la grandilocuencia artística de Luis de Granada y el lenguaje familiar de Santa Teresa y Bernal Díaz, la cordial abundancia cer: 
vantina, la elegancia florida de Solís, la variedad ingeniosa de Quevedo, la extrema concisión de Gracián. El estilo a la vez discursivo y lírico de Rousseau no es incompatible para el buen gustador con el analítico y preciso de Voltaire, ni la naturalidad de Manzoni lo es con la togada elegancia del Leopardi de las Obrecillas morales. Aquella labor de taracea del grande escritor franco-argentino, en donde el epíteto agudo - siempre el más feliz el de intención más satírica--, la frase oportuna, la cita rebuscada con fruición y vanidad de bibliófilo curioso, la definición lapidaria, el juego de vocablos travieso, el paréntesis, la nota, la reticencia, más interesante que el propio texto, conjunto sabio en donde mostrábase tanta paciencia como ingenio, tanto talento como cultura, mal se avenía con la prosa que le brotaba a Rojas "ex-abundantia cordis", aunque de períodos no mal cortados y lógicamente bien encadenados. Pero, vivir y dejar vivir. Sería muy aburrida la tierra si todos pensáramos y escribiéramos de igual modo.

Admito que el oído perciba cierta exuberancia en uno que otro pasaje de la Historia de la literatura argentina, y más en los libros apologéticos de la argentinidad; pero ¿dónde en esa historia el mentado floripondio? No negaré que el ojo experto pueda descubrir algunos desvanecidos en la trama, y qué le diremos a Groussac de Víctor Hugo? Afirmó, en definitiva, que la prosa de Rojas, no por ser en ocasiones oratoria, resulta gerundiana; y que si el crítico con su frase numerosa se desdobla a veces en conferenciante, sería injusto negarle, además de innegables elegancias de forma y persistente elocuencia, la precisión y concisión adecuadas cuando describe y define críticamente obras y autores. Cuando en el prólogo de Eurindia dijo haber trabajado reciamente la prosa, procurando lograr la mayor precisión y simplicidad con el deseo de poner en el menor número posible de páginas todo lo que necesitaba decir, no se engañó.

La verdad es que aquella frase despectiva trasuntaba, además del resentimiento ya dicho, acaso otros. Ignoro cuáles fueron las relaciones personales e intelectuales entre Rojas y Groussac con anterioridad a aquella fecha. Compruebo que en el magno banquete que los directores de Nosotros of recimos en I9i9 al maestro de Los que pasaban, en el cual hubo destacadas personalidades de las letras y la política, no estaban ni Leopoldo Lugones ni Ricardo Rojas. Sí Alejandro Korn, José Ingenieros, Ramón Cárcano, Carlos Vega Belgrano, Julio Roca, Carlos Ibarguren, Atilio Chiáppori, Alberto Williams, Eduardo Aguirre, Ernesto de la Cárcova, Luis Berisso, Fernández Moreno, Enrique Dickmann, entre tantos ancianos y jóveneses, Vẹrdad que la personalidad literariạ del historiador del Santiago 
de Liniers, del crítico de El viaje intelectual, del cronista viajero de Del Plata al Nígara no aparece tratada en el cuarto volumen de La literatura argentina, el relativo a "los modernos", pues Rojas adoptó el criterio, a mi juicio deformador de la historia, siendo la creación literaria argentina en buena parte contemporánea, de no escribir sobre los escritores entonces vivientes; sin embargo, a lo largo de toda la obra Groussac es tratado con el debido respeto, haciéndose mérito en ella de sus afirmaciones críticas y referencias bibliográficas. Dudo que en sus condiciones físicas "el francés desdeñoso y sabio", como por ahí lo calificó Rojas, haya podido examinar, como to he hecho yo, el centenar o poco menos de referencias elogiosas que se hacen en la Historia de la literatura a sus juicios y trabajos bibliográficos y eruditos, tanto más careciendo la primera edición de índice de nombres; pero habrá bastado aqquella alusión, unas pocas rectificaciones y una que otra reserva irónicamente cortés para ponerle los nervios de punta, cosa nada difícil. En fin: estos desencuentros son naturales en la vida literaria. Y para mí pienso que a Rojas no debía de haberle sorprendido la represalia tomada con su "impertinencia", pues él solía cobrárselas también (de carne somos) con amigos y enemigos. Ciertas omisiones injustificadas en su Historia, incluso en las noticias bibliográficas, confirman mi aseveración estrictamente técnica.

A pesar de las lagunas y errores de información que puedan señalarse en esta historia, el servicio prestado por Rojas a nuestra cultura es incalculable. En igual medida se han beneficiado con él la cátedra y el libro. A ese servicio agregó otros dos, con anterioridad y contemporáneamente: la publicación de la "Biblioteca argentina", que motivó una lamentable desavenencia con su amigo José Ingenieros, por haber éste acometido con pleno derecho hacia el mismo tiempo una empresa paralela en provecho de la cultura popular, y la fundación en 1922 del Instituto de Literatura Argentina, anexo a la cátedra de la Facultad. Las publicaciones de obras inéditas o mal conocidas, hechas bajo su dirección, y las monografías informativas y críticas inspiradas por él, si no todas de igual calidad, como compuestas muchas de ellas por alumnos bisoños en el oficio, muy meritorias más de una, por ejemplo las dedicadas a Martiniano Leguizamón por Julia Grifone, a Francisco Sicardi por Emma Napolitano, a Florencio Sánchez por Dora Corti y a Alfonsina Storni por María Teresa Orosco, han ampliado notablemente el conocimiento de nuestras letras. Agregaré los estímulos y contribuciones folklóricas, naturales, procediendo de quien aprovechó tanto material folklórico poéticamente vivido en la infancia 
santiagueña, en su primer libro en prosa, El país de la selva, en el cual estaban en germen sus dramas Elelin y La salamanca.

He escuchado a censores que reputan sin objeto la exhumación de obras de escaso o ningún valor literario. Tal sentencia es inadmisible. Ninguna contribución a la historia de la cultura es superflua, que tales son esas publicaciones cuando no se las valore como piezas literarias. De mí puedo decir que la lectura del primitivo texto del Juan Moreira, pergeñado por José Podestá, y la de obras que jalonan la historia del teatro argentino durante el siglo diecinueve, inéditas hasta su publicación por el Instituto, o casi inhallables, me ha sido muy útil, ensanchándome horizontes culturales. No menos aprecio la reedición de los ensayos novelescos de Mitre, Gutiérrez, Miguel Cané, el romántico, y el narrador naturalista José María Cantilo, sin dar por ninguna de tales primicias más de cuanto vale literariamente. La función de los institutos de investigación universitaria es dar a luz y ubicar bibliográficamente los documentos. Rojas no la practicó torcidamente. Piezas no menos carentes de valor estético publican y comentan los investigadores de las literaturas europeas más insignes. La labor del historiador o del crítico vienen después.

No olvidemos que el sabio y elegante escritor Juan Pablo Forner calificó de cartapelón en loor de las bragas del Cid el poema venerable, que tanta ingenua belleza poética encierra, cuando por primera vez la publicó Tomás Antonio Sánchez en I779. Me pregunto qué habría dicho Groussac, de haber vivido en I832, cuando Paulino París publicó el Roman de Berthe, origen de todos los sorprendentes hallazgos relativos a la epopeya francesa. ¿Se habría afiliado al bando de los eruditos, siéndolo él de buena ley, o entre los literatos clasicizantes? También debió él preguntárselo antes de barrer desdeñoso, como lo hizo, los materiales recogidos en la historia de Rojas. El exigente escritor, harto 'sabía cómo las más notables historias de las literaturas europeas representan la sedimentación y depuración de innumerables materiales acumulados por pacientes pesquisas, materiales insignificantes por sí muchos de ellos; renunciando, sin embargo, a un prudente criterio de relatividad, no quiso o no supo aplicarlo a lo nuestro.

La sociedad argentina ha exhibido en cualquier tiempo, junto a cínicos "nietos de Juan Moreira", cuando no a miserables Lauchas (he aludido a dos pícaros de Payró, de diferente estofa), ejemplos superiores de dignidad y rectitud de conducta. "El Santo de la Espada", como bautizó Rojas a San Martín, paradigma de modestia y decoro, es el más famoso, no 
el único de su talla en el campo moral. La vida llevada por Rojas, de estudio, trabajo, acrisolada honradez y renunciamiento a lo bullanguero y efímero nos exige, para ser justos, presentarlo asimismo como un ejemplo. Su indumentaria severa, su aire grave, con algo de pontifical cuando peroraba, sobre todo en la ancianidad, en círculos de discípulos o adictos, eran la corteza de una personalidad jugosa, familiar y cordial en la charla intima, en la cual chispeaba el buen humor. En los tiempos en que más lo traté no desdeñaba la buena mesa. En su evocación de Becher recordó con nostalgia "los ágapes nocturnos en el restaurante Ferrari, célebre -escuchemos a este nacionalista - por sus tallarines y su Chianti importado directamente; en el Restaurante de Gando, insigne por sus anguilas marinatas y sus Nebiolos; en el Restaurante Bismarck, egregio por su choucroute y su Agua de Oro". Sus ambiciones nunca fueron de vuelo bajo. Si las tuvo altas, políticas, las manifestó batallando por grandes causas; no se lo vio ensuciarse en los entreveros de comité; de ahí que, salvo aquella candidatura a senador por la Capital en que puso tantas esperanzas la opinión ilustrada porteña, no ocupara, él, ciudadano eminente y respetado, catedrático universitario, escritor, ilustre, orador elocuente, ningún lugar en las listas de candidatos de su partido. No digamos que porque era un hombre difícil; difícil sí, pero de sobornar con dudosos honores, en trueque de la complicidad en banderías partidarias. Se justipreciaba por lo que valia y esto no podemos afeárselo como una debilidad moral a quien pulió su personalidad en permanentes nobles afanes, mirando hacia cosas grandes y no ruines. Fue honrado por su obra con muchos títulos académicos y universitarios, pero no sé que los haya solicitado codiciosamente. Puedo of recer como ejemplo un caso en el cual tuve intervención personal. Cuando el ministro Rothe, del gobierno "de facto", creó en r932 la Academia Argentina de Letras, le fue ofrecido a Rojas, uno de los sillones. Lo rehusó, como era natural que lo hiciera un adversario del movimiento de septiembre., Pasados los años, durante la presidencia constitucional de Roberto Ortiz, se pensó que él no debía estar ausente de la corporación, desaparecidos ya los motivos de la repulsa. Fue Carlos Ibarguren, presidente de la Academia, el más empeñado en incorporarlo y me encargó de efectuar las primeras gestiones personales. Rojas no se negó abiertamente, antes admitió su posible consentimiento. Pero cuando Ibarguren lo visitó para confirmar la aceptación, Rojas, si bien declarảndose muy agradecido al honor que se le dispensaba y salvando la consideración que le merecía la Academia, declaró sencillamente que habiéndose negado la primera vez, prefería no volver șobre sus pasos, 
En alguna ocasión he escuchado la queja de que no alentó a los jóvenes escritores como lo hizo generosamente Lugones en artículos consagratorios, desde el primero que publicó en 1908 sobre El libro de los elogios de Enrique Banchs. Aparte de que en mi opinión no se debe juzgar a un maestro por los elogios que dispense - actitud que en ocasiones más tiene de la lisonja que del estímulo útil, y me guardo muy bien de referirme a Lugones, perspicaz descubridor de poetas - sé que Rojas, sin prodigarse en efusiones epistolares ni ejercer la crítica militante, formó y alentó en su cátedra y fuera de ella a discípulos y escritores que todavía le están reconocidos. Yo puedo dar fe del empeño que puso en algunos casos para verlos sobresalir y triunfar.

He trazado los rasgos más característicos de la fisonomía intelectual y moral de Ricardo Rojas, corrigiendo mi enfoque personal con líneas y colores pedidos a su obra impresa. Sé muy bien que no forman un retrato acabado. Son apenas un borrón. El leve sombreado no tuvo otro propósito que darle a mi amigo figura humana y no de ídolo hierático. Al hombre lo conoceremos aún mejor apenas se publiquen sus memorias, prometidas' en varios volúmenes. A juzgar por los recuerdos contenidos en su libro Retablo español, aquéllas serán de tanto interés como amenidad, uno de esos libros que perduran como Recuerdo de provincia, las Memorias de un viejo, de Víctor Gálvez, Juvenilia, Los que pasaban o los Recuerdos literarios, de García Mérou. Cuanto a su obra restante, que el ilustrado colega Enrique Anderson Imbert, en su breviario de Historia de la literatura bispanowericana se apresura a despachar en unos pocos renglones desdeñosos, hasta, diría, malévolos, y una imagen zumbona, sin la menor referencia a la capital Historia de nuestra literatura, pienso que ocupará largos años la atención de los estudiosos. No querría haber dado la falsa impresión de que no siento respeto por sus doctrinas éticas, estéticas y sociológicas con relación al desenvolvimiento espiritual de la Argentina. Un pensamiento constructivo como fue el suyo, inspirado en el antiguo ideal de integración social de América y desenvuelto fervorosamente en muchos libros, no puede ser juzgado, cualesquiera que sean las disidencias que suscite, sin un serio examen. Êste excede el cuadro del presente artículo.

ROBERTO F. GiUsti, Academia Argentina de Letras. 
